\title{
De la experiencia fenomenológica del conflicto armado hacia una experiencia significativa de la paz en el post acuerdo ${ }^{1}$ From a phenomenological experience of the armed conflict towards a significant experience of peace in the post agreement
}

\author{
Uva Falla Ramírez" \\ Juan Guillermo Velásquez Arias*
}

\section{Resumen}

El propósito de este artículo es analizar los procesos subjetivos de la experiencia significativa que viven algunas personas en contextos de violencia en Colombia. Para ello se recurre al análisis desde la perspectiva de la fenomenología de Alfred Schütz y de Paul Ricoeur. Se presenta un análisis fenomenológico que implica describir los sentidos otorgados al conflicto desde los cuales se interpreta la realidad y desde la cual llegan a conducirse. A partir de ese ejercicio analítico se captaron algunas señales que indican cambios en los sentidos otorgados al Acuerdo por

${ }^{1}$ Artículo producto de la investigación realizada entre el 2014 y 2015 titulada: Comprensión del significado que las y los trabajadores sociales atribuyen a la intervención social a partir de sus vivencias en el espacio de la acción profesional. Investigación financiada por la Universidad Colegio Mayor de Cundinamarca que se ocupó del significado subjetivo en la acción del Trabajo Social por parte del Grupo de investigación disciplinar en Trabajo Social y Tendencias contemporáneas desde la línea axiológica institucional. Parte de las reflexiones fueron presentadas en el evento: "Apuestas individuales que construyen en colectivo un territorio posible", Concejo municipal de Barrancabermeja y Universidad de la paz- Unipaz. Barrancabermeja Santander, octubre 19 de 2015.

* Trabajadora social, Magíster en Planeación y Desarrollo Socioeconómico. Candidata a Doctora en Trabajo Social, Universidad Nacional de la Plata (UNLP), Argentina. Docente investigadora de la Universidad Colegio Mayor de Cundinamarca, Colombia. Correo electrónico: ufalla@unicolmayor.edu.co

** Trabajador social. Candidato a Magister en investigación social interdisciplinar. Universidad Distrital Francisco José De Caldas. Investigador Auxiliar en la Universidad Colegio Mayor de Cundinamarca -Colombia- del Grupo de investigación Disciplinar en Trabajo Social y Tendencias Contemporáneas. Correo electrónico: jngvelar@gmail.com

Recibido: 09 de junio de 2017 Aprobado: 29 de septiembre de 2017 ISSN: 0122-1213 (Impreso) ISSN: 2389-993X Doi: 10.25100/prts.v\%vi\%i.4666 
la paz, desde un proyecto preconcebido hacia una serie de actos reales, un objeto de análisis fenoménico de donde surge la pregunta por la paz como apertura de la experiencia social. Por tal razón, se presentan algunas consideraciones que más que ser puntos de cierre son reflexiones sobre la paz como horizonte temático de la sociedad colombiana, no tanto en su conocimiento sino en su existencialidad.

Palabras clave: Conflicto; Construcción de paz; Responsabilidad; Reconocimiento; Imaginario; Significado subjetivo; Fenomenología social.

\section{Abstract}

The purpose of this paper is to analyse the subjective processes of the significant experience lived by some people in contexts of violence in Colombia. In order to do this, we use analysis from the perspective of phenomenology of Alfred Schütz and Paul Ricoeur, in which imagination converts the construction of peace as a possible world. The intention is to perform a phenomenological analysis describing the meanings given to the conflict from which the reality is interpreted and which drive behaviour. From this analytical exercise it was possible to capture some signals that indicate changes in the meanings granted to the Agreement for peace, from a preconceived project to a series of real acts, an object of phenomenal analysis which gives rise to the question of peace as an opening of social experience. Therefore, rather than closed positions, some considerations are presented as reflections about peace as the thematic horizon of Colombian society, not so much in its knowledge but in its existence.

Keywords: Conflict; Peacebuilding; Responsibility;Acknowledgement; Imaginary; Subjective meaning; Phenomenology.

Sumario: 1. Introducción y contexto del significado 2. Consideraciones metodológicas. 3. Tránsitos conceptuales. Entre el reconocimiento y la filantropía. 4. De la gestión de la investigación al proceso reconstituido del método fenomenológico: entre el reconocimiento y el anonimato. 5. Consideraciones finales. 6. Bibliografía 


\section{Introducción y contexto del significado}

Para iniciar esta reflexión se parte de unos cuestionamientos que en su momento (2015) se hicieron respecto al proceso de negociación entre el Gobierno Nacional y las Fuerzas Armadas Revolucionarias de Colombia, Ejército del Pueblo (FARC-EP). Precisamente, después de celebrar el punto cuarto de la agenda referido a víctimas, punto en el que se han presentado-y le preceden- una serie de procesos jurídico-políticos y técnico-operativos del que sobrevienen discrepancias y consensos en las orientaciones de sentido subjetivas. Ellas dan cuenta de las expresiones respecto de algunos actores, específicamente sobre el comunicado conjunto $\mathrm{N}^{\circ} 60$ que se refería a la creación de una jurisdicción especial para la paz (JEP):

El componente de justicia prevé que, a la terminación de las hostilidades, de acuerdo con el DIH, el Estado colombiano otorgará la amnistía más amplia posible por delitos políticos y conexos. Una ley de amnistía precisará el alcance de la conexidad. En todo caso no serán objeto de amnistía o indulto las conductas tipificadas en la legislación nacional que se correspondan con los delitos de lesa humanidad, el genocidio y los graves crímenes de guerra, entre otros delitos graves como la toma de rehenes u otra privación grave de la libertad, la tortura, el desplazamiento forzado, la desaparición forzada, las ejecuciones extrajudiciales y la violencia sexual. Estos delitos serán objeto de investigación y juzgamiento por parte de la Jurisdicción Especial para la Paz (Alto Comisionado para la Paz, 2015).

Es en este contexto que se busca contribuir a los análisis y debates que se han venido gestando y consolidando a partir de la disertación de los siguientes interrogantes que en este escrito no se resuelven en su totalidad pero sí permiten orientar la discusión. ${ }^{2}$

- ¿Cuáles son los sentidos otorgados al conflicto desde la experiencia significativa de las víctimas?

${ }^{2}$ En ese momento ya se sabía de la existencia del Acuerdo y estaba próximo a su refrendación por parte del constituyente primario. El resultado del Referendo fue: el 'NO' gana con el 50,21 \% de los votos (6.431.376 votos) contra el SI 49,76\% (6.377.482). República de Colombia Registraduría Nacional. Plebiscito 2 de octubre de 2016. (Recuperado Mayo 30 de 2017). 
- ¿Cómo interpretan las personas los hechos de que fueron víctimas por esas fuerzas insurgentes y con quienes el gobierno colombiano promovió el proceso de paz?

- ¿Cómo prevén las víctimas conducirse en su cotidianidad a partir de los acuerdos firmados?

- ¿Cómo evitar en los procesos de búsqueda de la paz, la tendencia a un reconocimiento compasivo y lograr la lógica de la compasión solidaria, digna y justa?

Son cuestionamientos que tienen que ver con procesos en donde los seres humanos adquieran una centralidad basada en la igualdad, el respeto y la justicia social y donde la máxima sea dirigida hacia la universalidad en los derechos y deberes para todos y todas. Porque una sociedad que se piensa desde los intereses particulares corre el riesgo de concebir un sistema jurídico, político y económico en términos del beneficio de unos pocos hacia otros muchos y, considerar los derechos humanos no como lo que son sino como beneficio otorgado dadivosamente. Visto de esa manera lo que provoca es mayor exclusión y desigualdad. Es una sociedad de economía burguesa que, parafraseando a Hegel, constituye un espectáculo de miseria y corrupción.

A partir de lo expuesto en el documento se podrán distinguir cuatro apartados que evidencian el tránsito en el ejercicio analítico. En el primero, se presentan los elementos metodológicos tenidos en cuenta para asumirlo como un ejercicio descriptivo desde una perspectiva fenomenológica. El segundo aborda la cuestión del reconocimiento y la filantropía en el marco de la discusión del papel del Estado y la sociedad civil. Posteriormente, se evidencia el acoplamiento llevado a cabo entre los referentes analíticos y los significados otorgados al conflicto desde la experiencia existencial de los sujetos entrevistados, junto con el análisis realizado. Por último, se presentan las consideraciones finales.

\section{Consideraciones metodológicas}

El proyecto de investigación buscó acercarse a la comprensión de los significados subjetivos construidos por trabajadores sociales en formación 
que fueron víctimas de la violencia en la zona de Barrancabermeja en Santander. Los actores armados del conflicto ejercieron como forma de control del territorio actos de violencia expresados en la desaparición de sus padres o hermanos y de masacres de las cuales fueron testigos.

Para la recolección de la información se realizaron entrevistas y se organizó un grupo focal con jóvenes estudiantes de Trabajo social de últimos semestres de formación. El tema de discusión fue la firma del punto cuatro de la agenda, que en su momento fue coyuntural porque ello permitía prever la cercanía de la firma final del acuerdo de paz con las FARC-EP.

Una vez se transcribió la grabación de la información recolectada, se procedió a su análisis ubicando los textos según las categorías de análisis referidas al significado subjetivo. Esto permite hacer un ejercicio meramente descriptivo de los sentidos expresados por las personas entrevistadas en concordancia con los intereses de esta perspectiva.

La fenomenología social no pretende hacer explicaciones casuísticas o hacer generalizaciones que promuevan la explicación de leyes. La idea es describir la experiencia subjetiva, presentar algunas hipótesis que guíen nuevos procesos de investigación. Aspectos que el grupo ha continuado indagando, no solo sobre el tema de la paz sino en los diferentes ámbitos de desempeño del Trabajo Social.

\section{Tránsitos conceptuales. Entre el reconocimiento y la filantropía}

En el contexto de la lectura foucaultiana de los estudios de gubernamentalidad (Mantilla, 2006, Muñoz-Onofre, 2014, 2015) la centralidad en los procesos dirigidos a mejorar las condiciones de vida de la población en general, la adquiere la sociedad civil. Desde el supuesto de gobernar, el Estado traslada problemáticas sociales como la pobreza bajo la premisa de la corresponsabilidad. De esta manera, se relega a un segundo plano el protagonismo del Estado al promover organizaciones no gubernamentales y asociaciones civiles e iniciativas de carácter filantrópico que asume la misma empresa privada bajo el modelo de Responsabilidad Social Empresarial. De ello se deriva que el Estado en el ejercicio de 
sus responsabilidades sea cada vez menor. Tal como plantea Matus: "el reconocimiento compasivo universal es una virtud bajo sospecha" (2008, p. 71). Pero ¿qué papel juega la política en este contexto? Al respecto Adela Cortina plantea:

El Sector político, en el nivel nacional, transnacional o internacional, tiene por tarea hacer justicia. Lo cual significa hoy en día proteger los derechos civiles, políticos, económicos, sociales y culturales de los habitantes de cada comunidad política (sea cual fuere su forma de pertenencia a ella, también de los inmigrantes) y trabajar por protegerlos de cualquier ser humano, dentro del horizonte de una Ciudadanía Social Cosmopolita (2008, p. 65).

En este sentido, la responsabilidad no solamente recae en la sociedad civil; es el Estado y sus instancias gubernamentales quienes deben garantizar los derechos de primera, segunda e incluso tercera generación logrando así una sincronía Estado-sociedad civil-sistema político, en busca del reconocimiento de la dignidad humana de los más pobres y de los excluidos, de las víctimas. En general, de los seres humanos que integran una sociedad. Porque desde la declaración de los derechos humanos se encuentra presente el legítimo derecho del reconocimiento de la dignidad humana, que no tiene precio, no tiene valor de intercambio.

En este contexto -y en los procesos de búsqueda de la paz e incluso en los procesos de post acuerdo-conviene recordar los planteamientos de Apel que Adela Cortina referencia como la ética de la comunicación en la que reconoce tres elementos:

1) Entre los interlocutores se reconoce un igual derecho a la justificación del pensamiento y a la participación en la discusión. 2) Todos los afectados por la norma puesta en cuestión tienen igual derecho a que sus intereses sean tenidos en cuenta a la hora de examinar la validez de la norma, aun cuando sólo fueran interlocutores virtuales. 3) Cualquiera que desee en serio averiguar si la norma puesta en cuestión es o no correcta debe estar dispuesto a colaborar en la comprobación de su validez. De ahí que sea preciso asumir un Principio de corresponsabilidad que complementa al principio individual de responsabilidad (Cortina, 2006, p. 21). 
Es decir, sobreponiendo el planteamiento de Apel se tiene en mente respecto al punto número uno el establecer un diálogo con todos los actores involucrados. Respecto al punto dos, se considera al pueblo la ciudadanía en general; y por último, atañe a los compromisos adquiridos después de un proceso de refrendación, que no solamente se circunscriban a él sino a los procesos, relacionamientos, acciones de todo tipo que busquen su materialidad en la vida cotidiana. En todo esto, se encuentra un profundo respeto por la dignidad, que se expresa a través de la afirmación de derechos y el desarrollo de capacidades, donde la legitimidad yace en el reconocimiento de los intereses universales y no individuales y donde las luchas por el reconocimiento no solo sean la de los que padecen la exclusión.

Ahora bien, ubicados en este ethos epocal ${ }^{3}$, en los procesos de investigación e intervención que de ellas se derivan, igualmente se encuentra presente el compromiso ético con la justicia social, la dignidad en el marco del respeto por los Derechos Humanos, el reconocimiento y la inclusión social. Dicho compromiso ético se configura en el marco de lo político, más allá de entenderlo como su correlato de lo partidista. Lo ético político se configura a partir de la convicciones universales y no particularistas, tiene que ver con las convicciones ideológicas de los seres humanos y no con los desempeños de las profesiones.

La ética implica una actitud coherente con la palabra y con la acción, la ética se aprende en la praxis, en la vida cotidiana, en las relaciones y hechos compartidos, se construye alrededor de una constante problematización de la realidad social desde la perspectiva que le significa ver y verse no como beneficiario pasivo de planes, programas y proyectos sino como sujeto social digno de exigir sobre los mismos:

(...) la labor ética del trabajador y trabajadora social, se posiciona a favor de la equidad y de la justicia social, en la perspectiva de la universalización de los accesos a bienes y servicios relativos a programas y políticas

${ }^{3}$ La noción de ethos epocal es tomado del planteamiento de Fóscolo que la define como "las cosmovisiones valorativas que rigen la sociedad, a lo largo de la historia» (2006, p. 49). Ethos que cumple una función de bisagra en los relacionamientos entre las teorías éticas, las relaciones sociales y su incidencia en la intervención del Trabajo Social. 
sociales, la ampliación y la consolidación de la ciudadanía y la garantía de los derechos civiles, políticos y sociales de las clases trabajadoras (Falla, Gómez y Rodríguez, 2011, p. 211).

En este sentido se debe ser coherente con la acción para aportar a la construcción de relaciones sociales fundamentadas en la igualdad en el marco de los Derechos Humanos, la inclusión social y la lucha por el reconocimiento, y en la preservación por la vida. Por esta razón el ejercicio de análisis que a continuación se presenta, parte del proceso investigativo desarrollado desde la perspectiva fenomenológica que se formula en términos de Belvedere (2006) como el "anonimato del sujeto" que perfila recobrar los contenidos de la conciencia como forma de subvertir lo instituido y como forma de construcción de una vida digna del hombre en su mundo cotidiano a partir de la relación responsabilidad-reconocimiento. Para complementar el análisis de las experiencias significativas del conflicto, se parte también de la fenomenología hermenéutica de Paul Ricoeur; en concreto, se toma la problematización de la imaginación en el discurso y la acción como posibilidad para pensar la paz en la apertura de mundos posibles.

\section{De la gestión de la investigación al proceso reconstituido del método fenomenológico: entre el reconocimiento y el anonimato}

La fenomenología social en esta aproximación es la matriz que permite comprender al ser humano en su experiencia vital en el mundo de la vida cotidiana. Hombres y mujeres desde que nacen se relacionan con sus predecesores, contemporáneos, sucesores y asociados. La fenomenología social los rescata de la anonimidad y los pone en el centro del mundo de la vida. Proceso que se desarrolla en una actitud natural y en el que se producen una serie de relaciones de carácter intersubjetivo tipificándolos como desplazados, víctimas, desposeídos, sobrevivientes, excluidos, etc.

En la fenomenología social, hay dos aspectos que son pertinentes para este análisis: el primero tiene que ver con entender que la categoría mundo de la vida cotidiana, como aquí es abordada, no es desde una 
perspectiva filosófica (Husserl, Lévinas, Bretano, entre otros ${ }^{4}$ ); sino desde la perspectiva social que incorpora desde la epoké de segundo orden de Schütz la temporalidad como forma para comprender y describir la construcción social en el mundo de la vida cotidiana.

En este sentido, la construcción de una vida digna del hombre en su mundo cotidiano constituye un reto en la dinámica de lo social, político, jurídico, cultural y económico. En el actual contexto nacional se entiende al ser humano como ser individual que llega a este mundo donde todo ya está dado, donde le precede un sistema de lenguaje, de instituciones, de prácticas culturales que han sido objetivadas y construidas históricamente. El hombre llega a vivir en un mundo que sus antecesores han construido pero que al relacionarse con él puede comprender y ser comprendido. Es desde esta misma perspectiva que el mundo de la vida puede ser subvertido por el hombre que vive en una actitud natural, como lo plantea Schütz:

(...) el mundo de la vida cotidiana es la región de la realidad en que el hombre puede intervenir y que puede modificar mientras opera en ella mediante su organismo animado. Al mismo tiempo las objetivaciones y sucesos que se encuentran ya en este ámbito (incluyendo los actos y las acciones de los otros hombres) limitan su libertad de acción. Lo ponen ante obstáculos que pueden ser superados, así como ante barreras que son insuperables. Además, solo dentro de este ámbito podemos ser comprendidos por nuestros semejantes, y solo en él podemos actuar junto con ellos. Únicamente en el mundo de la vida cotidiana puede constituirse un mundo circundante, común y comunicativo. El mundo de la vida cotidiana es, por consiguiente, la realidad fundamental y eminente del hombre (Schütz y Luckmann, 2009, p. 25).

${ }^{4}$ En el contexto latinoamericano, la fenomenología filosófica trascendió el interés por el hombre y la cultura como un acercamiento al interés de los procesos subjetivos en torno "al ser latinoamericano" (...) "Se identifica al Círculo Latinoamericano de Fenomenología (CLAFEN) liderado por los profesores Antonio Zirión Quijano quien ha hecho las traducciones de las ideas, de Husserl, y creador del diccionario para traducir a Husserl. Rosemary Rizo-Patrón ha desarrollado importantes investigaciones sobre teoría del conocimiento, antropología y ética, en diálogo con la obra de Husserl y observando las rupturas y filiaciones de la fenomenología con la filosofía moderna Husserl y Rosemary Rizo-Patrón de Lerner" (Martin, 2016, p16). 
Desde esta perspectiva de análisis las experiencias vividas configuran a los hombres. Son las que permiten definir un ámbito de sentido común. Ámbito que a la vez es divergente a partir de la relación con los otros y desde donde puede delinear o crear planes de vida sobre los cuales en una actitud consciente pone interés. Este acto, claramente definido, es lo que permite que hombres y mujeres se concentren en la realización de sus proyectos, de sus metas, de la satisfacción de sus necesidades, etc. De esta forma, mujeres y hombres viven en sus actos, de sus actos y por sus actos. Es decir, se vive por lograr aquello sobre lo cual le conduce a la efectuación de los mismos.

En ese trasegar se generan las experiencias de vida, es decir, las vivencias que son los proyectos pre concebidos que han sido realizados y que por eso mismo han sido cargados de significado. Son las experiencias de vida que son rememoradas por contener un significado subjetivo.

Por lo tanto, partimos de entender que el significado subjetivo se encuentra en el estrato del fenómeno del significado que toma como punto de partida el acto cumplido o las vivencias terminadas que la acción en curso ha producido y sobre la que se ha efectuado la reflexión. Esto es, que solo adquiere sentido aquello que se ha vivido y sobre lo que se ha reflexionado. Solo las vivencias pasadas pueden tener un significado.

El objeto de la comprensión es la vivencia significativa, "el significado solo puede entenderse en este caso como la mirada atenta dirigida no a una vivencia que transcurre sino que ya ha pasado" (Schütz, 1993, p. 82). Es decir, la experiencia de vida que hemos vivido, que hemos vivenciado y que por un acto reflexivo de atención lleva a que se le otorgue el significado y el sentido a la forma de ver la vida. Ello lleva a que las personas construyan los futuros actos proyectados y a partir de allí, según la perspectiva de la fenomenología social, se actúe de tal o cual manera. En síntesis, también en consideración con el sistema de tipificaciones que se han construido a lo largo de la vida.

A partir de lo expuesto se presentan las verbalizaciones que evidencian los contenidos de conciencia de algunos actores $^{5}$ que han vivenciado el

\footnotetext{
${ }^{5}$ Actores que serán identificados en adelante como E1, E2 y E3 y sus expresiones en cursiva.
} 
fenómeno del conflicto armado y su "acto proyectado" o posicionamiento frente al proceso de paz. Con tales testimonios se realiza un análisis fenomenológico que implica describir los sentidos otorgados al conflicto desde los cuales interpretan la realidad y llegan a conducirse en ella.

Significados que no pueden entenderse de forma lineal sino como una indicación aproximada del significado subjetivo que no representan a la totalidad de un colectivo pero que igualmente tienen demandas. Experiencias del conflicto que fraguan sentimientos, percepciones pensamientos e ideas sobre la paz:

(...) para mí la paz tiene otro significado porque si yo viví la violencia, yo sé lo que es la violencia pura. Yo conocí la guerrilla y saber que sacaban a la gente de las casas, que por mi cuadra metían secuestrados. Cuando yo vi que el guerrillero violaba a la niña más bonita del barrio y si se oponía la mataban. Cuando yo viví eso, eso es muy dificil de creer que pueda llegar a haber paz (E.1).

De esta manera y por la relación de la experiencia vivida tanto por ella como por sus antecesores, por aquellos que han vivido una existencia cargada de sufrimiento, exclusión, violencia que los hace reconocerse como víctimas que han dejado un mundo configurado, objetivado su dolor que está presente en la memoria, y por lo mismo, está el deber ético de reconfigurar o mejor reedificar ese mundo de la vida cotidiana.

... y es que nos tocó sufrir tanto, tanto económicamente como moralmente. O sea uno dice no hay educación que le cure como esas heridas del alma, ni programas que de pronto el gobierno le da a uno. A nosotros nos dieron plata que por la reparación, pero es que es una plata que uno dice... no nos llena... todo ese sentimiento todo ese vacio y esa frustración (E2).

Por esto es importante problematizar el conflicto como dimensión de la vida cotidiana en tanto se inscriba en las experiencias personales que privan de las relaciones intersubjetivas la construcción de un mundo común $y$ configurando una vida cotidiana-no cotidiana que imposibilita la "experiencia existencial del ser con los otros" (Jaramillo, 2003, p. 77), es 
decir "encontrarse con el otro", del "trabajar juntos" o del "ir hacia el otro" y del "compartir con el otro".

Ya he curado muchas heridas, ya mi corazón está limpio, uno ya no lo corresponde. O sea, uno tener los propios hijos de uno, ya uno como que ve la perspectiva de otro punto de vista, entonces ya uno dice no, yo cuido mis hijos, ya gracias a Dios no me falta nada, no me faltó nada por la pérdida de mi papá, entonces ya uno dice: No, ya puedo vivir tranquila ya soy entre comillas feliz. ¿Sí? Pero entonces uno dice aquellas personas que nos les fue tan bien, que han sido más marcadas que uno, que sufrieron más que uno, entonces uno dice, uno tiene que ponerse en el lugar de esas personas, Dios mío, esas personas que en el momento de hoy están de pronto ehhh aguantando hambre, que no tienen un techo, un trabajo, entonces uno dice bueno, ahi es donde la guerrilla debe pagar (E.2).

En la vida cotidiana se da la reciprocidad de perspectivas que permiten la distribución del conocimiento desde donde se origina el conocimiento como tipificaciones que los hombres construyen a lo largo de su historia (Schütz, 1974, pp. 42-45); en este sentido el conflicto es una construcción que hacen los sujetos a partir de sus vivencias y que son transmitidas por el conocimiento social, y es a partir de las relaciones intersubjetivas y estos conocimientos que se pueden construir sentidos del conflicto mediante las experiencias de este fenómeno, experiencias que ponen en tensión las acciones que se vienen adelantando y las proyecciones y anticipaciones que los actores realizan:

Porque uno no cree en el proceso de paz, porque uno fue el que vivió esa situación, el que vivió esa violencia, entonces uno dice ¿cómo va a hacer el gobierno para reparar daños que no se pueden reparar? Porque no se pueden reparar (E1).

(...) yo veo que primero que todo deberíamos saber que la guerrilla, cometió horrores, cometió crímenes de lesa humanidad secuestros, torturas ¿Por qué ellos no pagan por esos crímenes? Quieren es que... haya una inclusión política, pero ellos no quieren pagar los crímenes que cometieron (E1). (...) no ha habido participación de las personas que son las víctimas de este proceso, ahi deberían estar las víctimas y no los políticos (E2).

No... no estamos convencidos con el proceso (E3). 
Como se evidencia, en la experiencia existencial del ser resaltan los contenidos de conciencia referidos al costo de la violencia que se asume en la mesa de negociación y como forma de imposición en la cual no se ven representados. En este punto cabe retomar un planteamiento de Schütz:

Nuestro propio ambiente social se halla al alcance de todos en todas partes; un Otro anónimo -cuyos objetivos debido a su anonimia, desconocemospuede ponernos bajo su control, junto con nuestro sistema de intereses y significatividades. Cada vez somos menos dueños de determinar por nosotros mismos lo que es y lo que no es significativo para nosotros. Nos vemos obligados a tomar en cuenta, tal como son, las significatividades impuestas política, económica y socialmente que están fuera de nuestro control. Para ello necesitamos conocerlas (2003, p. 128).

Por otro lado, se vincula a este análisis el planteamiento de Paul Ricoeur, respecto al papel de la imaginación en el discurso y la acción (2002) y, en este caso, en relación con el sentido otorgado al conflicto y su implicación con el imaginario que rescata la experiencia como apertura de la imaginación. Por tanto, cabe precisar los términos imagen, imaginación e imaginario, el primero lo refiere Ricoeur con:

El término "imagen" se aplica al dominio de las ilusiones, es decir, de las representaciones que, para un observador externo o en una reflexión ulterior, se dirigen a cosas ausentes o inexistentes, pero que, para el sujeto y en el instante en que está entregado a ellas, hacen creer en la realidad de su objeto (Ricoeur, 1999, p. 199).

Para Ricoeur, la cuestión de la imagen se relaciona con la ficción en tanto que evocación de cosas ausentes, pero implica también un direccionamiento del sujeto, y es en estos dos polos (el objetivo-subjetivo) que se vuelve problemática y que será resuelta en el tránsito de la cuestión perceptiva hacia una discursiva que se refleja en el abordaje del término imaginación.

La imaginación es la apercepción, la visión súbita de una nueva pertinencia predicativa, a saber, una manera de interpretar la pertinencia en la falta de pertinencia. Se podría hablar aquí de asimilación predicativa, a fin de 
descartar que la semejanza es un proceso homogéneo al propio proceso predicativo. Nada se toma aquí entonces de la vieja asociación de ideas en tanto atracción mecánica entre átomos mentales. Imaginar es en primer lugar reestructurar campos semánticos (Ricoeur, 1999, p. 202).

Por lo señalado anteriormente, dicha restructuración introduce la cuestión de la imaginación en el campo del lenguaje a partir de la vinculación de la metáfora como elemento dinamizador del uso del lenguaje, en concreto, un ejercicio de innovación semántica que posibilita ver "como si...", desplazándose entre la cuestión del cambio de sentido, el acercamiento entre campos semánticos distantes y la emergencia de significados, que en suma "dice algo nuevo de la realidad" (Ricoeur, 2008, p. 27), en este sentido Ricoeur saca el problema de la imagen como cuestión histórica y el de la representación como cuestión psicológica.

como si la metáfora diera un cuerpo, un contorno, un rostro al discurso... Pero, ¿cómo? A mi juicio, en el momento en que surge un nuevo significado de las ruinas de la interpretación literal, es cuando la imaginación ofrece su mediación específica" (Ricoeur, 1999, p. 202).

Con este enfoque Ricoeur soportará su formulación de imaginario social el cual está constituido por una dimensión temporal, la cual vincula la imaginación con la acción que se anuda con la fenomenología que trasciende la experiencia individual; esto al atender la relación entre la ficción y la acción que posibilita el ejercicio de variación imaginativa al vincular el esquema motivacional con la narración. Así, los motivos para aluden al ejercicio de anticipación de los posibles cursos de acción y lo narrativo a su vinculación con el porqué con las explicaciones que dan cuenta de lo hecho o lo sucedido.

Daremos un paso decisivo en dirección del imaginario social, si reflexionamos sobre las condiciones de posibilidad de la experiencia histórica en general. La imaginación está implicada allí en la medida en que el campo histórico de la experiencia tiene también una constitución analógica (Ricoeur, 1999, p. 208). 
Ricoeur expone que la dimensión temporal implica la posibilidad de configurar múltiples composiciones de acuerdo al posicionamiento del yo en las relaciones con los antecesores, contemporáneos y sucesores en los cuales se presenta la trasmisión de conocimientos, valores y tradiciones.

Hay un campo histórico de experiencia porque mi campo temporal está ligado a otro campo temporal mediante lo que se ha denominado una relación de acoplamiento (Paarung), según la cual, un flujo temporal puede acompañar a otro flujo (Ricoeur, 1999, p. 209).

Es en este sentido que la imaginación cumple una función mediadora en el principio trascendental de que "el otro es un yo semejante a mí'” (Ricoeur, 1999, p. 209) en tanto elemento que constituye el campo histórico.

La tarea de esta imaginación productora es, en particular, mantener vivas las mediaciones de todo tipo que constituyen el vínculo histórico y, entre ellas, las instituciones que objetivan el vínculo social y transforman incansablemente el nosotros en ellos (Ricoeur, 1999, p. 210).

A partir de lo expuesto, se presenta una serie de relacionamientos que se dan entre imaginación, discurso y acción, uno de ellos es la cuestión del sentido. Por sentido Ricoeur (2002) aludirá al procedimiento de suspensión del significado que supera la imagen como percepción, y en cuyos procesos se encuentran la reducción y la totalización. Por tanto, la superación de la imagen implica la representación simbólica del vínculo social, es decir, Ricoeur aludirá a la acción de imaginar como el método para crear mundos posibles.

Para Ricoeur (2002) la acción es entendida como una posibilidad que se complementa con el ejercicio de variación imaginativa que se encuentra en tensión entre lo finito y lo infinito. El primero alude a la ideología como necesidad de imaginarse y representarse donde se rescata la categoría motivos porque de Alfred Schütz. El segundo comprende a la utopía como juego de posibilidades que comprende un ejercicio de imaginación anticipatoria y, por tanto, forma parte de la categoría motivos para. La relación discurso acción se encuentra en la posibilidad de la acción de 
vincularse con los ejercicios de variación imaginativa. Así, la ficción viene a ser una redescripcción de la acción y la creación como un ejercicio de pensar posibilidades al evocar las cosas ausentes e inexistentes.

Asumiendo el corpus de análisis desde Ricoeur se puede identificar una intención narrativa orientada a la acción, donde las expresiones subjetivas se remiten a las cosas hechas pero que logran vincular la experiencia vivida con ámbitos temporo-espaciales sociales.

Uno de los vínculos identificados es la violencia, la cual moviliza anticipaciones imaginativas y fijaciones identitarias en un mismo proceso constitutivo del sentido, como lo expresan respecto a su pasado: cuando yo conoci la guerrilla y saber que sacaban a la gente de las casas, que por mi cuadra metían secuestrados. (...) Cuando yo viví eso, eso es muy dificil de creer que pueda llegar a haber paz. En el subrayado se pueden identificar ejercicios anticipatorios que llegan a vincular la experiencia de la violencia con acciones imaginativas de una posible no paz. De manera similar se identifican fijaciones identitarias desde la experiencia de la violencia que las vinculan como víctimas no hay educación [no hay compensación económica] que le cure como esas heridas del alma.

En las narrativas también se identifica que esta misma violencia se presenta como posibilidad de algo inconcluso ya he curado muchas heridas, ya mi corazón está limpio, uno ya no lo corresponde. Un reclamo da cuenta de su búsqueda no ha habido participación de las personas que son las víctimas de este proceso, ahi deberían estar y no los políticos.

Otro tipo de relación, es la que establece consigo mismo y sus contemporáneos; (...) pero entonces uno dice aquellas personas que también nos les fue tan bien, que han sido más marcadas que uno, que sufrieron más que uno, entonces uno dice, uno tiene que ponerse en el lugar de esas personas, y sucesores. O sea, uno al tener sus propios hijos ya como que ve la perspectiva desde otro punto de vista, relaciones que resignifican su experiencia actual.

Pero estas orientaciones desde el presente hacia el pasado y el futuro pueden dar cuenta de prácticas imaginativas sociales como son la utopía y la ideología. La cuestión de estas prácticas, de acuerdo con las narrativas de las participantes, es que se presentan como horizontes móviles, siendo 
el presente una bisagra que articula proyectos de acción y sujeciones con antepasados, contemporáneos y sucesores como posibilidad, una forma de vida, un futuro, a la expectativa de algo mejor, pero con demandas sociales.

En este caso "la violencia" es aquella bisagra que captura las narraciones y sus narradores, que actualizan las tradiciones y prácticas discursivas, entre la violencia-no violencia, paz-no paz, la violencia como vínculo con el pasado y el presente de sus trayectos vitales. Pero, como lo señala Ricoeur: "Aunque, en efecto, los hechos son imborrables y no puede deshacerse lo que se ha hecho, ni hacer que lo que ha sucedido no suceda, el sentido de lo qué pasó, por el contrario, no está fijado de una vez por todas" (1999, p. 49). La "paz" como utopía viene a ser un espacio impreciso frente a las experiencias que encierran las posibilidades de acción como actor social, siendo a la vez la "paz" el espacio de posibilidad para sus sucesores. Como se puede identificar, se presenta un conflicto entre expectativas de acción hacia la paz y experiencias vividas de la violencia.

\section{Consideraciones finales}

En el momento en que el NO resultó ser rotundo y sonó a los oídos de muchos -vale decir de todos aquellos que votamos por el SI- hubo un dolor profundo, por creer que no era posible ese país tan deseado, sin violencia, con mejores condiciones de inclusión social. Hoy en día se enfrenta ese significado subjetivo entre el temor -que llevó a votar por el NO- y al mismo tiempo el amor, ese deseo-amor supremo por la paz que hoy convoca a todo un pueblo a buscar las salidas en las que seamos capaces de brindar un horizonte más próspero a nuestros sucesores. Quizá la fenomenología social pueda contribuir en la búsqueda de respuestas a esas preguntas que se plantean para ser consideradas por todo aquel que quiera seguir con este tipo de apuestas.

Para concluir, se busca recobrar los planteamientos de la fenomenología social porque se ha olvidado que el mundo en que vivimos nos determina, nos marca, nos hace "hacer" y nos hace "ser". Pero también donde se despliegan las acciones, se concretan los proyectos, se construye diariamente. Entonces cabe preguntarse ¿cuál es esa realidad del mundo de 
la vida que día a día estamos construyendo?, ¿Cuál es el mundo de la vida cotidiana que estamos dejando para nuestros sucesores?, ¿Cómo potenciar la tarea de la sociedad civil en este proceso?, ¿Cómo revitalizar una ética que se interese o se preocupe por hacer más amable la vida cotidiana?, ¿Cómo pensar y diseñar políticas públicas más justas, equitativas y dignificantes?

Las respuestas a estos y muchos otros interrogantes están en todos nosotros, en la búsqueda por construir una política económica y social que derive en una cultura de paz. Paz que se encuentra en el horizonte temático de la sociedad colombiana no tanto en su conocimiento sino en su existencialidad.

Las anteriores, son preguntas pensadas no para llegar a un cierre de este escrito sino para ser consideradas en la búsqueda de caminos que lleven a planteamientos pertinentes frente a la política pública en el país. En momentos en que a pesar de los resultados del Plebiscito, el Acuerdo por la paz dejó de ser un proyecto preconcebido, y se convirtió en un acto real, un objeto de análisis fenoménico de donde surge la pregunta por la paz como apertura de la experiencia social.

\section{Referencias bibliográficas}

Agnes, H. (1987). Sociología de la Vida Cotidiana. Barcelona: Ediciones 62 S.A. Alto Comisionado para la Paz. (2015). Comunicado conjunto \# 60 sobre el Acuerdo de creación de una Jurisdicción Especial para la Paz. Recuperado de http:/www.altocomisionadoparalapaz.gov.co/procesos-y-conversaciones/ documentos-y-comunicados-conjuntos/Documentos\%20compartidos/2015/ comunicado60septiembre15VEsp.pdf

Belvedere, C. (2006). Semejanza y comunidad: Hacia politización de la fenomenología. Buenos Aires: Biblos.

Cortina, A. (2006). Ética pública desde una perspectiva dialógica. Prospectiva, $11,13-24$.

Falla, U.; Gómez, S. y Rodríguez, R. (2011). La intervención en lo social y la construcción de un proyecto político del Trabajo Social. Tabula Rasa, 15, 195-219.

Fóscolo, N. (2006). Desafíos éticos del Trabajo Social latinoamericano: Paradigmas, necesidades, valores, derechos. Buenos Aires: Espacio Editorial. 
Hegel, G. (1968). Filosofía del Derecho: introducción de Carlos Marx. Buenos Aires: Claridad. Recuperado de http://upcndigital.org/ ciper/biblioteca/ Filosofia\%20moderna/Hegel\%20-\%20Filosofia\%20del\%20Derecho.pdf

Jaramillo, M. (2003). La dimensión de lo político en el mundo de la vida. Revista Praxis Filosófica, 17, 1-23. Doi: https://doi.org/10.25100/pfilosófica. v0i17.3055

Mantilla, G. (2006). Gubernamentalidad y Seguridad Democrática: una aproximación a las prácticas de seguridad democrática en Colombia desde la filosofía política de Michel Foucault. Bogotá: Uniandes.

Matus, T. (2008). Alegorías de Dulle Griet en el capitalismo tardío. Comentario a la ponencia central de Adela Cortina. Revista de Trabajo Social, 74, 71-81. Recuperado de https://repositorio.uc.cl/bitstream/ handle/11534/6503/000507981.pdf? sequence=1\&isAllowed=y

Muñoz-Onofre, D. (2014). Gubernamentalidad bélica: potencias de un concepto localizado para pensar las guerras contemporáneas. Nómadas, 41, 203-219. Recuperado de http://nomadas.ucentral.edu.co/nomadas/pdf/ nomadas_41/41_12M_Gubernamentalidad_belica.pdf

Muñoz-Onofre, D. (2015). Pensar La Guerra (En Colombia) Más Allá De La Tanatopolítica. Athenea Digital, 15(4), 61-80. Recuperado de http:// atheneadigital.net/article/view/v15-n4-munoz/1591-pdf-es

Ricoeur, P. (1999). La lectura del tiempo pasado: memoria y olvido. Madrid: Universidad Autónoma de Madrid.

Ricoeur, P. (2002). La imaginación en el discurso y la acción. En Ricoeur, P. Del texto a la acción: ensayos de hermenéutica II. México: Editorial Fondo de cultura económica.

Ricoeur, P. (2008). Palabra y símbolo. En Ricoeur, P. Hermenéutica y acción: de la hermenéutica del texto a la hermenéutica de la acción (pp. 21-38). Buenos Aires: Prometeo.

Schütz, A. (1974) El problema de la realidad social. Buenos Aires: Amorrortu Editores.

Schütz, A. (1993) La construcción significativa del mundo social: Introducción a la sociología comprensiva. Madrid: Editorial Piados.

Schütz, A. (2003) Estudios sobre teoría social. Escritos II. Madrid: Amorrortu Editores.

Schütz, A. y Luckmann T. (2009). Las Estructuras del Mundo de la vida. Madrid: Amorrortu Editores. 
Cómo citar este artículo:

Falla-Ramírez, U. y Velásquez, J. G. (2017). De la experiencia fenomenológica del conflicto armado hacia una experiencia significativa de la paz en el post acuerdo. Prospectiva, 24, 49-68. Doi: 10.25100/ prts.v\%vi\%i.4666 